\title{
Cryopreservation of Different Strains of the Euryhaline Rotifer Brachionus plicatilis Embryos
}

\author{
Joebert D. Toledo, ${ }^{* 1}$ Hisashi Kurokura, ${ }^{* 2}$ and Heisuke Nakagawa*3 \\ (Received Feburary 12, 1991)
}

\begin{abstract}
Cryopreserevation of different strains of Brachionus plicatilis symmetrical stage embryos was conducted. One S-type strain, namely Yashima-S (YS), and three L-type strains, namely Yashima-L (YL), Nagasaki (NG), and Hamana (HA), were used. Symmetrical stage embryos in $10 \%$ DMSO-28\% sea water solution were frozen at $-196^{\circ} \mathrm{C}$ using a two-step freezing procedure; the embryos were first cooled slowly from $-5^{\circ} \mathrm{C}$ to $-20^{\circ} \mathrm{C}$ at a rate of $0.3^{\circ} \mathrm{C} / \mathrm{min}$ and then cooled rapidly by direct transfer to liquid nitrogen. Frozen samples were thawed in a gently stirred water bath at room temperature. A mean survival rate of $36 \%$ after 30 days storage in liquid nitrogen of HA strain was significantly lower than YS $(55 \%), \mathrm{YL}(58 \%)$, and NG $(54 \%)$, and is due likely to its relatively larger embryo volume. There was no significant difference in the intrinsic rate of increase $(r)$ between strains among clones taken from the cryopreservation or unfrozen control group. The results also indicate that various strains of $B$. plicatilis embryos can be cryopreserved without seriously altering their reproductive capability. The freezing method described could be of great potential in aquaculture and in future studies on rotifer genetics.
\end{abstract}

Cryopreservation has been widely employed in experimental biology, medicine and animal breeding. Its usefulness in aquaculture, however, has been limited to sperm cryopreservation. ${ }^{1,2}$ Development of cryopreservation techniques for aquaculture could lead to gene banking and effcetive management of hatchery facilities regardless of the natural spawning season.

Because larval mouth size sets the upper limit of prey size, the size of the rotifer Brachionus plicatilis a euryhaline rotifer extensively used as a live food for fish and prawn larvae, is crucial in its utilization. A variety of first-feeding larvae ingests prey sizes between 50 to $100 \mu \mathrm{m}$ while larvae with large mouths can accommodate a wider size range. ${ }^{33}$ Body size variation among B. plicatilis strains has been reported by Fukusho and Okauchi, ${ }^{4}$ Ito et al.,, and Snell and Carillo. ${ }^{0}$ Maintenance of a certain strain with the desired morphological and genetic characteristics is often at risk of contamination, and total collapse of cultures is sometimes unavoidable. In addition, rotifer culture is costly and requires routine work. A reliable cryopreservation technique for various strains of rotifer could therefore alleviate such problems. In our previous paper, ${ }^{7)}$ we demonstrated a successful cryopreservation method for the separated symmetrical stage embryos of $B$. plicatilis. However, the size variation of embryos among strains is a possible important factor which can affect the results of the cryopreservation. This paper describes the cryopreservation of four strains of B. plicatilis embryos and evaluates their viability in terms of the intrinsic rate of increase of population after storage in liquid nitrogen.

\section{Materials and Method}

One S-type strain, namely Yashima-S (YS), and three L-type strains, namely Yashima-L (YL), Nagasaki (NG), and Hamana (HA), of B. plicatilis were used. Each strain was cultured separately in $3 l$ flasks containing $28 \%$ and $25^{\circ} \mathrm{C}$ sea water. Flasks were aerated, and rotifers fed Nannochloropsis sp. Density was kept constant at 10 to 50 individuals $/ \mathrm{m} l$ by renewing the culture every 3 or 4 days. These strains have distinct

*1 Aquaculture Department, Southeast Asian Fisheries Development Center, P. O. Box 256, Iloilo City, Philippines.

*2 Fisheries Laboratory, Faculty of Agriculture, University of Tokyo, Maisaka, Hamana, Shizuoka 431-02, Japan (黒會 寿: 東京大学農学部附属水産実験所).

*3 Faculty of Applied Biological Sciences, Hiroshima University, Higashi Hiroshima 724, Japan (中川 平介：広島大学生物生座学部). 
morphological characteristics and have been continuously maintained in the laboratory for three years.

Synchronization of embryo stage and separation of embryos from ovigerous females were done following Toledo and Kurokura. ${ }^{7)}$ Briefly, juveniles from the culture stock of each rotifer strain were passed through as $80 \mu \mathrm{m}$ plankton net and finally collected in $40 \mu \mathrm{m}$ net. These were separately raised in $2 l$ flasks following the culture method previously described. Separated juveniles laid their first eggs after 16 to $20 \mathrm{~h}$ under such conditions. As soon as a majority of the separated culture laid their first eggs, the rotifers were again collected with a $40 \mu \mathrm{m}$ net and washed into $20 \mathrm{~m} l$ screw cap test tubes. The eggs were separated from ovigerous females by vigorous mixing with a vortex mixer for 10 to 15 min. The test tubes were left to stand for about 10 min to allow the separated embryos to settle. Separated embryos were pipetted out and placed in a watch glass to remove unwanted debris. Collected embryos were raised in $5 \mathrm{ml}$ petri dishes containing filtered sea water through 0.45 $\mu \mathrm{m}$ membrane filter, of which salinity was $28 \%$, and incubated in a rotary shaker-incubator (Model SCS-R, Sanki Seiki Co.) at $25^{\circ} \mathrm{C}$ and $50 \mathrm{rpm}$ until used. Separated embryos of all strains reached the symmetrical stage about 7 to $11 \mathrm{~h}$ after eggs were laid. Separated embryos of each strain were photographed at $200 \mathrm{x}$ magnification before freezing for the measurement of embryo volume and the volume $(0.524$ length $\times$ width ${ }^{2}$ ) was calculated following the method of Yufera. ${ }^{8)}$ Symmetrical stage embryos were frozen following a two-step freezing procedure described by Toledo and Kurokura. ${ }^{7}$ The embryos were incubated at room temperature in $10 \%$ DMSO $(\mathrm{v} / \mathrm{v})$ in the filtered sea water for $30 \mathrm{~min}$. Then, the embryos at the density of $100-200$ individuals $/ \mathrm{m} l$ were pipetted into $0.5 \mathrm{ml}$ plastic insemination straws, heat sealed, and immediately frozen in a Program Freezer (FFP, Osaka Sanso Kogyo Ltd.). The straws were cooled from room temperature to $-5^{\circ} \mathrm{C}$ at a rate of $5^{\circ} \mathrm{C} / \mathrm{min}$, at which point ice seeding was induced by jetting chilled nitrogen gas in the middle of the straws and held for $5 \mathrm{~min}$ for temperature equilibration. The straws were then cooled to $-20^{\circ} \mathrm{C}$ at a rate of $0.3^{\circ} \mathrm{C} / \mathrm{min}$ and held for $5 \mathrm{~min}$ before rapid cooling by direct transfer to liquid nitrogen. All samples were stored in liquid nitrogen for at least $\mathbf{3 0}$ days before thawing.

Frozen samples were thawed by immersing the straws in a gently-stirred water bath at room temperature. Thawed samples were immediately expelled in $5 \mathrm{ml}$ petri dishes and rediluted twice by adding an equal volume of the filtered sea water at 2-min intervals. The embryos were then washed with fresh sea water of the same salinity, transferred to cell well plates (Corning Cell Wells 255820), and placed in the rotary shaker-incubator at $25^{\circ} \mathrm{C}$ and $50 \mathrm{rpm}$ until hatching. Nannochloropsis sp. was provided in each cell well as food for newly-hatched neonates. Survival was expressed as a percentage of the number of hatched embryos relative to the number of embryos recovered.

To evaluate the viability of each strains after cryopreservation, 5 individuals with first laid eggs were pipetted randomly and inoculated in $30 \mathrm{~m} l$ Erlenmeyer flasks containing $10 \mathrm{~m} l$ of the filtered sea water with $1 \times 10^{7}$ Nannochloropsis sp. cells $/ \mathrm{m} /$. Subsequently, 5 individuals with first laid eggs separated from the culture stock as described above were treated in the same way and served as the unfrozen control. One $\mathrm{ml}$ of Nannochloropsis sp. at the density of $1 \times 10^{7}$ cells were added daily to ensure an adequate supply of food. The rotifers were preserved in $1 \%$ formalin on the fifth day and the total number of individuals in each flask was counted. Intrinsic rate of increase $(r)$ was caluculated according to the formula $d N / d t=r N$, where $N$ and $t$ represent the number of animals and lapsed time in days, respectively.

Statistical analysis was performed using a oneway or two-way ANOVA followed by student's $t$-test to compare differences between means at $P=0.05$.

\section{Results}

Table 1 shows the variation in embryo volume among strains of rotifer. The mean embryo volume of the YS strain $\left(297 \mu \mathrm{m}^{3}\right)$ was significantly smaller than YL, NG and HA strains. No significant difference in embryo volume was observed between YL $\left(367 \mu \mathrm{m}^{3}\right)$ and $\mathrm{NG}$ (355 $\left.\mu \mathrm{m}^{3}\right)$. HA embryos had the largest volume (398 $\mu \mathrm{m}^{3}$ ) among the four strains examined.

The mean survival of symmetrical YS, YL, NG and HA embryos frozen by two-step freezing and stored in liquid nitrogen for 30 days is shown in Table 2. No significant differences in survival 
have been reported to have a higher freezing tolerance when compared with other embryonic stages. ${ }^{14)}$ The present results also concur with Euteneuer et al. ${ }^{13)}$ who demonstrated that frozen amictic eggs survive better than adults or neonates.

While mammalian embryo preservation is rapidly developing, ${ }^{18}$ ) advance in aquatic embryo preservation is relatively slow. ${ }^{2,18,17)}$ In the preservation techniques of $B$. plicatilis strains, Lubenz et al. ${ }^{18)}$ proposed a technique in which amictic females were preserved at $4^{\circ} \mathrm{C}$ in refrigerator. Their technique needs intricate handling during the preservation period at present and cost problems were anticipated for commercial use on a large scale. On the contrary, cryopreservation technique needs no handling during the preservation period except the supply of liquid nitrogen and greater merits can be expected. We have shown in this paper that separated symmetrical stage embryos of YS, YL, NG and HA strain $B$. plicatilis can survive storage in liquid nitrogen for at least 30 days without serious changes in their reproductive capability. Although longer storage in liquid nitrogen should be tested, we do not foresee any change in viability since biological activity of cells which can survive freezing below $-130^{\circ} \mathrm{C}$ ceases ${ }^{9)}$. No further loss of viability was observed in mouse embryos stored at $-196^{\circ} \mathrm{C}$ for 27 to 29 months. ${ }^{10)}$ By following or modifying the cryopreservation method described in this study, clones of a specific strain of $B$. plicatilis having the desired genetic and morphological characteristics can be conveniently stored in liquid nitrogen without altering their viability. Therefore, the present results have great potential in fish and prawn hatchery management.

\section{Acknowledgment}

This study was partially supported by the Japan Ministry of Education, Science and Culture in the form of a scholarship grant to the senior author. We thank Luis Ma. Garcia for critically reading the manuscript. We are also grateful to Dr. K. Hirayama, Nagasaki University and Dr. S. Yamashita and Dr. H. Hirata, Kagoshima University for providing the rotifer strains.

\section{References}

1) A. P. Scott, and A. M. Baynes: J. Fish Biol., 17, 707-739 (1980).

2) L. Stoss: in "Fish Physiology" (ed. by W.S. Hoar and J. Randall) Vol. IXB Academic press, New York, 1983, pp. 305-350.

3) J. R. Hunter: in "Marine Fish Larvae" (ed. by R. Lasker) Washington Sea Grant Program, Seattle, 1981, pp. 34-77.

4) K. Fukusho and M. Okauchi: Bull. Natl. Inst. Acuacult., 3, 107-109 (1982).

5) S. Ito, H. Sakamoto, M. Hori, and K. Hirayama: Bull. Facul. Fish. Nagasaki Univ., 51, 9-16 (1981).

6) T. W. Snell and K. Carillo: Aquaculture, 17, 359-376 (1984).

7) J. D. Toledo and H. Kurokura: Aquaculture, 91, 385-394 (1990).

8) M. Yufera: Hydrobiologia, 147, 319-322 (1987).

9) P. Mazur: Am. J. Physiol, 247, 245-255 (1984).

10) S. P. Leibo, J. J. McGrath, and E. Cravalho: Cryobiology, 15, 257-271 (1978).

11) I. Rumengen and K. Hirayama: Proc. Second Asian Fish. Forum, 33-36 (1989).

12) C. E. King, H. B. Bayne, T. K. Cannon, and A. E. King: Hydrobiologia, 104, 85-88 (1983).

13) S. Euteneuer, E. Lubzens, and E. Fishler: Spec. Publ. Europ. Maricult. Soc., 8, 211-218 (1984).

14) S. Okamoto, M. Tanaka, H. Kurokura, and S. Kasahara: Nippon Suisan Gakkaishi, 53, 2093 (1987).

15) M. J. Taylor: Cryoletters, 10, 69-72 (1989).

16) E. Asahina and T. Takahashi: Cryobiology, 15, 122-127 (1978).

17) J. D. Toledo, H. Kurokura, and S. Kasahara: Nippon Suisan Gakkaishi, 55, 1661 (1989).

18) E. Lubzens, G. Kolodny, B. Perry, N. Galai, R. Sheshinski, and Y. Wax: Aquaculture, 91, 23-47 (1990).

19) D. G. Whitingham, M. F. Lyon, and P. H. Glenister: Gen. Res. Camb., 29, 171-181 (1979). 